Supporting information

\title{
Laser Crystallization of Organic-Inorganic Hybrid Perovskite Solar Cells
}

Taewoo Jeon ${ }^{\dagger}$, Hyeong Min Jin ${ }^{\dagger}$, Seung Hyun Lee ${ }^{\dagger}$, Ju Min Lee $e^{\dagger}$, Hyung Il Park ${ }^{\dagger}$, Mi Kyung $\mathrm{Kim}^{\dagger}$, Keon Jae Lee ${ }^{*}$ Byungha Shin ${ }^{*} \dot{t}$ and Sang Ouk Kim ${ }^{*}, \dot{\dagger}$

*E-mail:byungha@kaist.ac.kr; sangouk.kim@kaist.ac.kr

This file includes:

Figure S1-S9

Table S1 
a

\section{Laser scanned area}

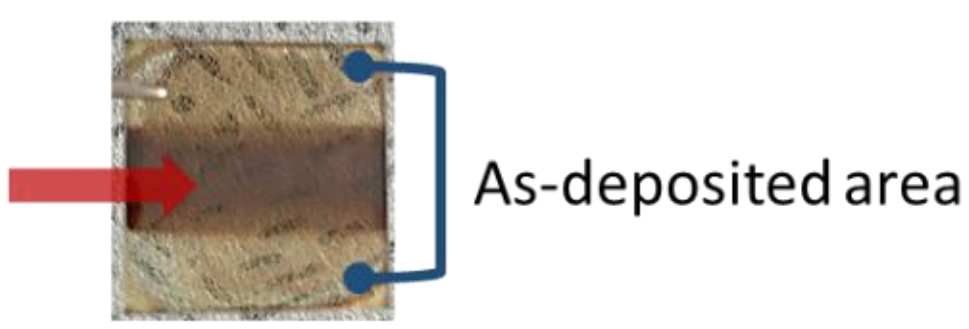

b

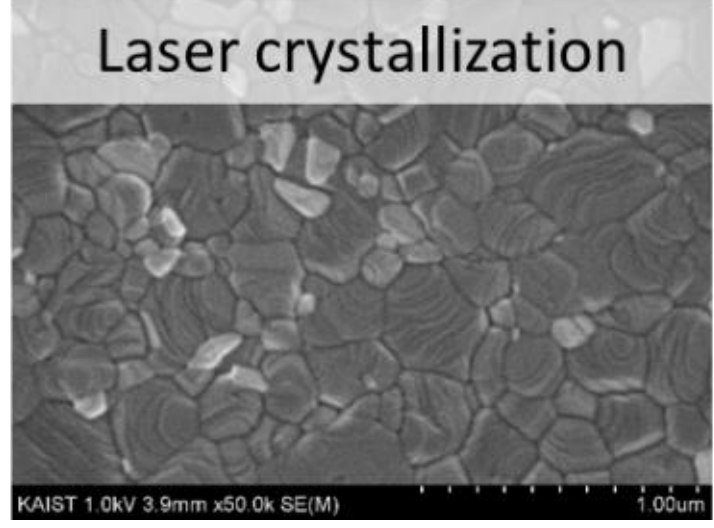

C

As-deposited

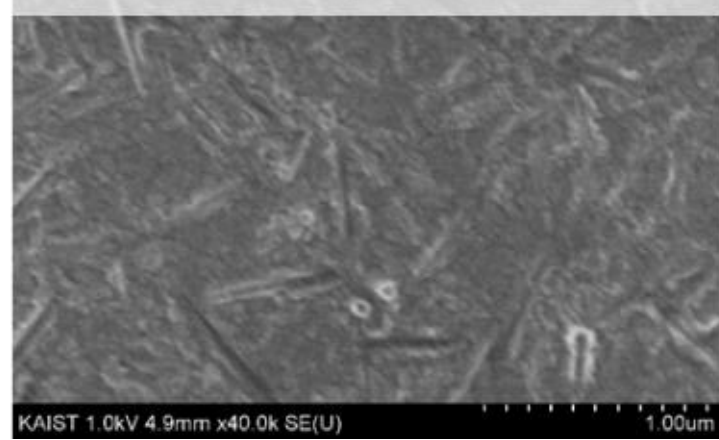

Figure S1. Photo and SEM images of laser-crystallized perovskite and as-deposited precursor. a. Photograph of partially laser-crystallized $\mathrm{MAPbI}_{3}$ layer. Color difference between laser scanned area (dark brown) and as-coated area (transparency) is obvious, indicating phase transformation to perovskite. Film morphologies visualized by SEM image of $\mathbf{b}$. laser-crystallized perovskite $\mathbf{c}$. as-deposited precursor film. 


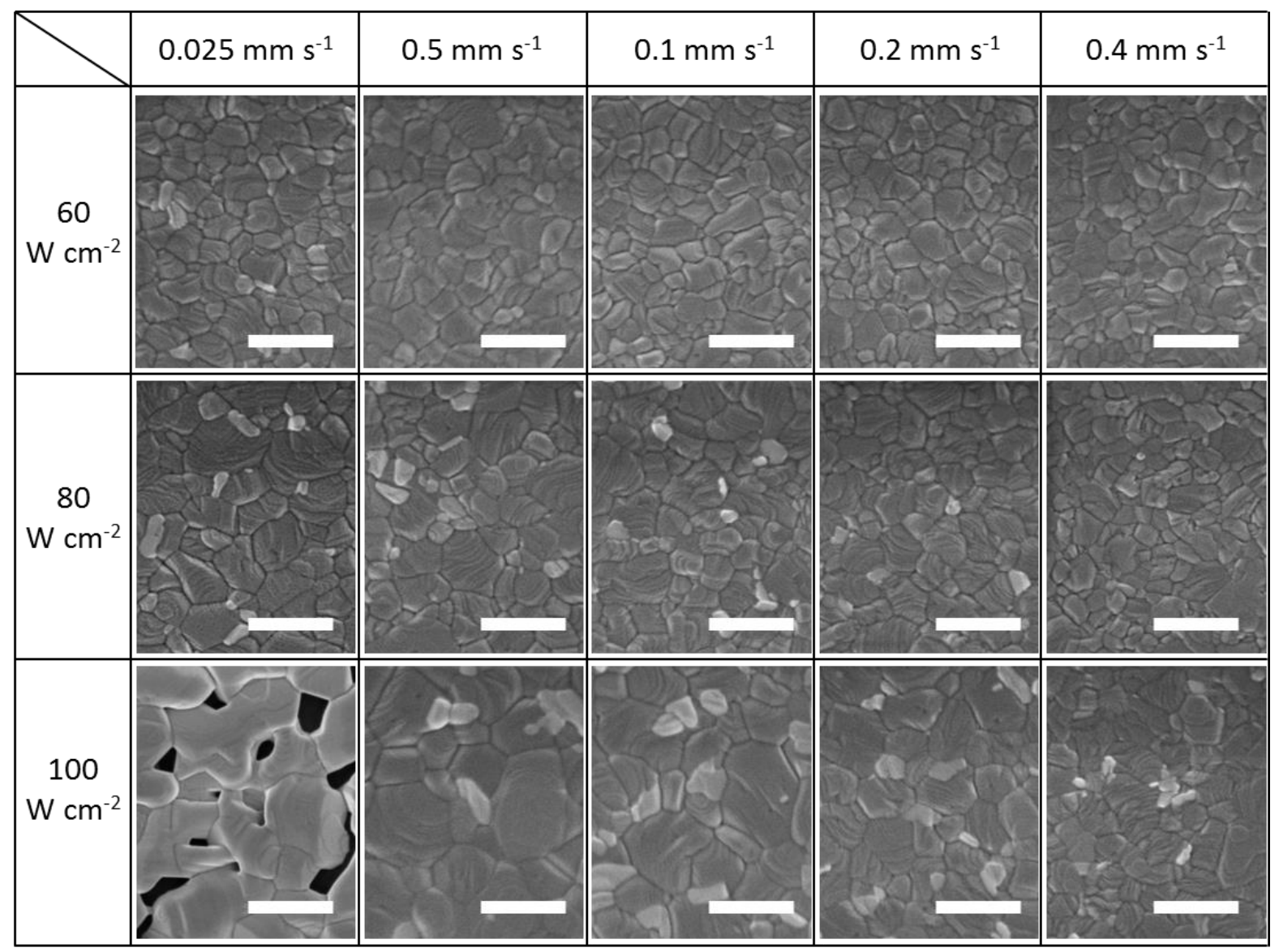

Figure S2. SEM image of $\mathrm{MAPbI}_{3}$ morphology controlled by various laser irradiation conditions (scale bar: $\mathbf{5 0 0} \mathbf{~ n m}$ ). $\mathrm{MAPbI}_{3}$ precursor layers were exposed to laser beam with power density and scan rate ranging 60 to $100 \mathrm{~W} \mathrm{~cm}^{-2}$ and 0.025 to $0.4 \mathrm{~mm} \mathrm{~s}^{-1}$, respectively. Controlled irradiation of laser with different experimental conditions results in wide-range of $\mathrm{MAPbI}_{3}$ perovskite morphology. Grain size scales with increased power density and decreased scan rate. 


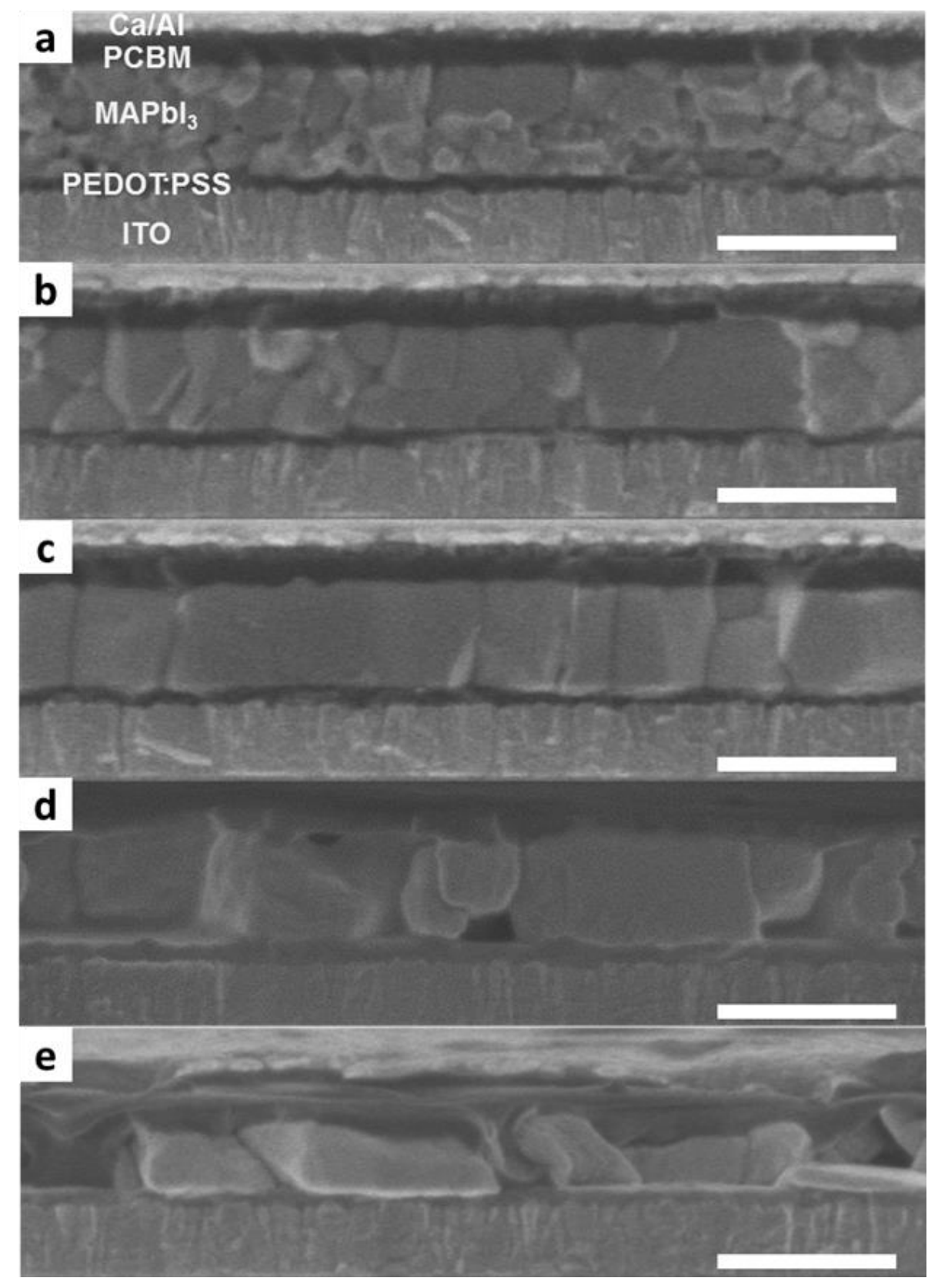

Figure S3. Cross-sectional SEM images of laser-crystallized $\mathrm{MAPbI}_{3}$ perovskite solar cells with increased power densities (scale bar: 500 nm). a. 40, b. 60, c. 80, d. 100 and e. $120 \mathrm{~W} \mathrm{~cm}^{-2}$ with constant scan rate of $0.1 \mathrm{~mm} \mathrm{~s}^{-1}$ (film thickness: $310 \mathrm{~nm}$ ). As power density increases up to $80 \mathrm{~W} \mathrm{~cm}^{-2}$, grain tends to be well-defined with reduced grain boundaries while maintaining uniform film morphology. Further increase of laser power over $80 \mathrm{~W} \mathrm{~cm}^{-2}$ induces film non-uniformity. 


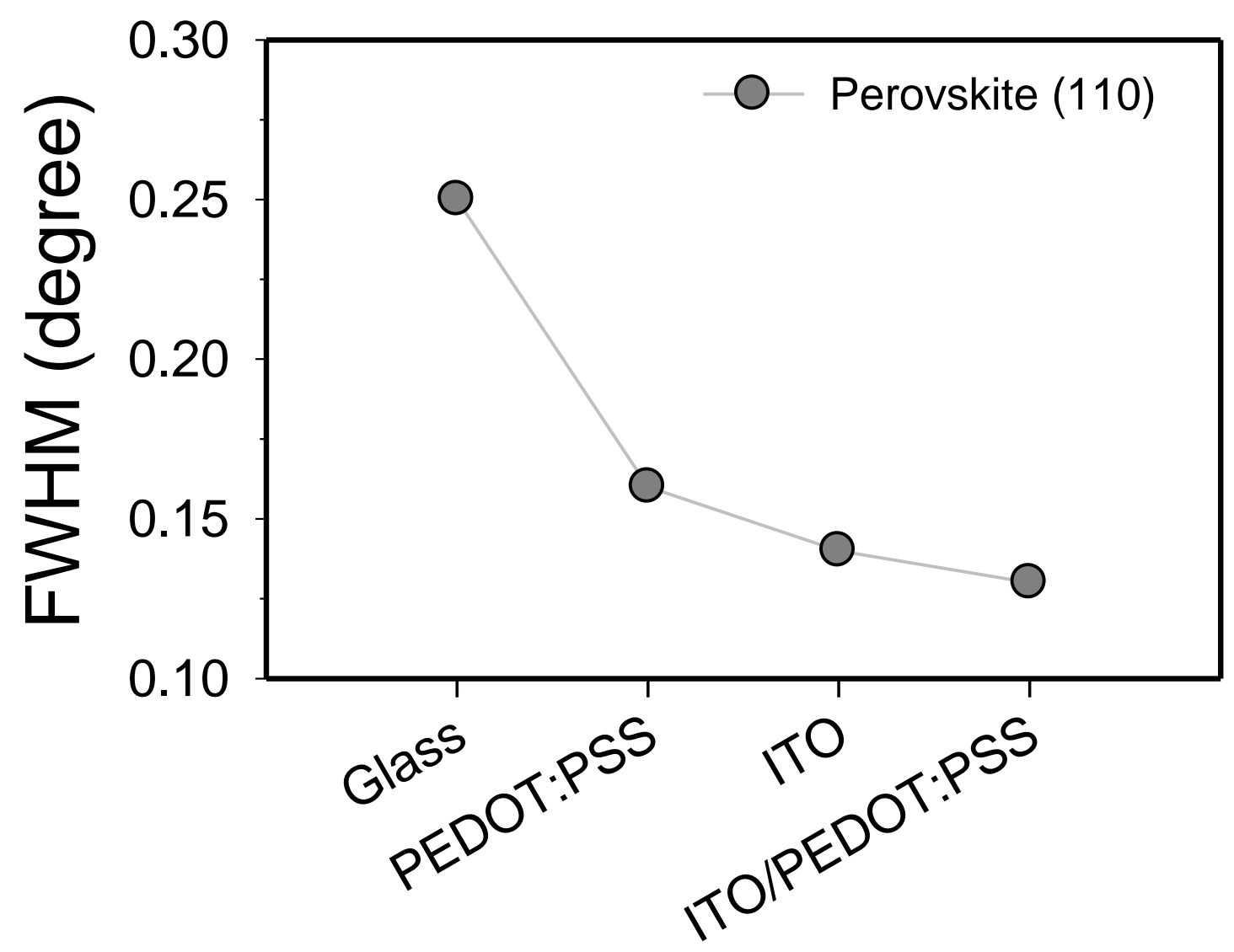

Figure S4. FWHM values with different substrates and interlayers. The decrease tendency is due to enhanced temperature rise by photothermal heating due to synergetic combination of interfacial charge transport layers (Figure 3b). 


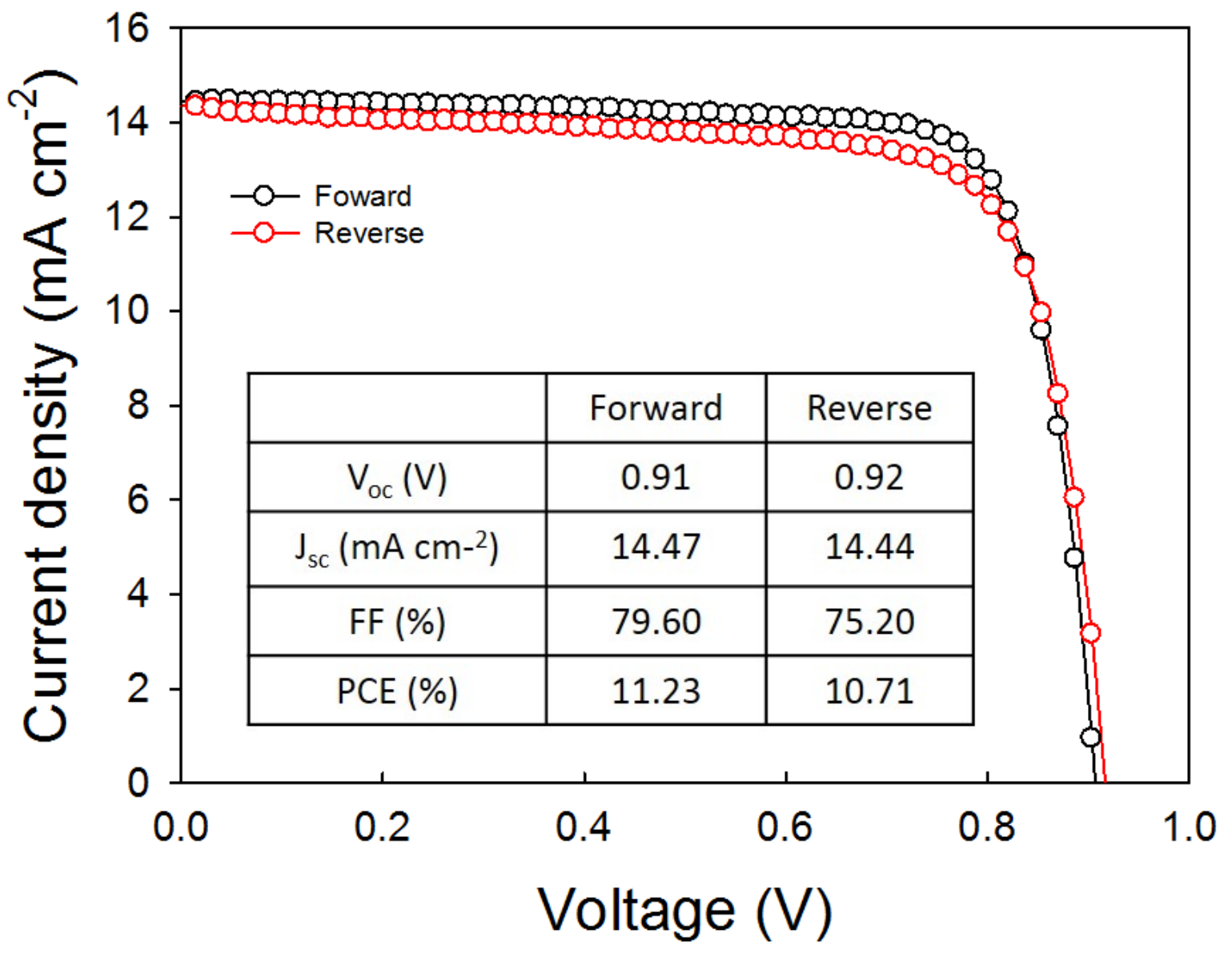

Figure S5. Hysteresis characteristics of laser crystallized perovskite solar cells. The J-V curves are measured under AM 1.5G conditions with $10 \mathrm{~ms}$ of delay time and $15 \mathrm{mV}$ voltage steps. Minimal hysteresis is observed and inset table summarizes solar cell parameters. 

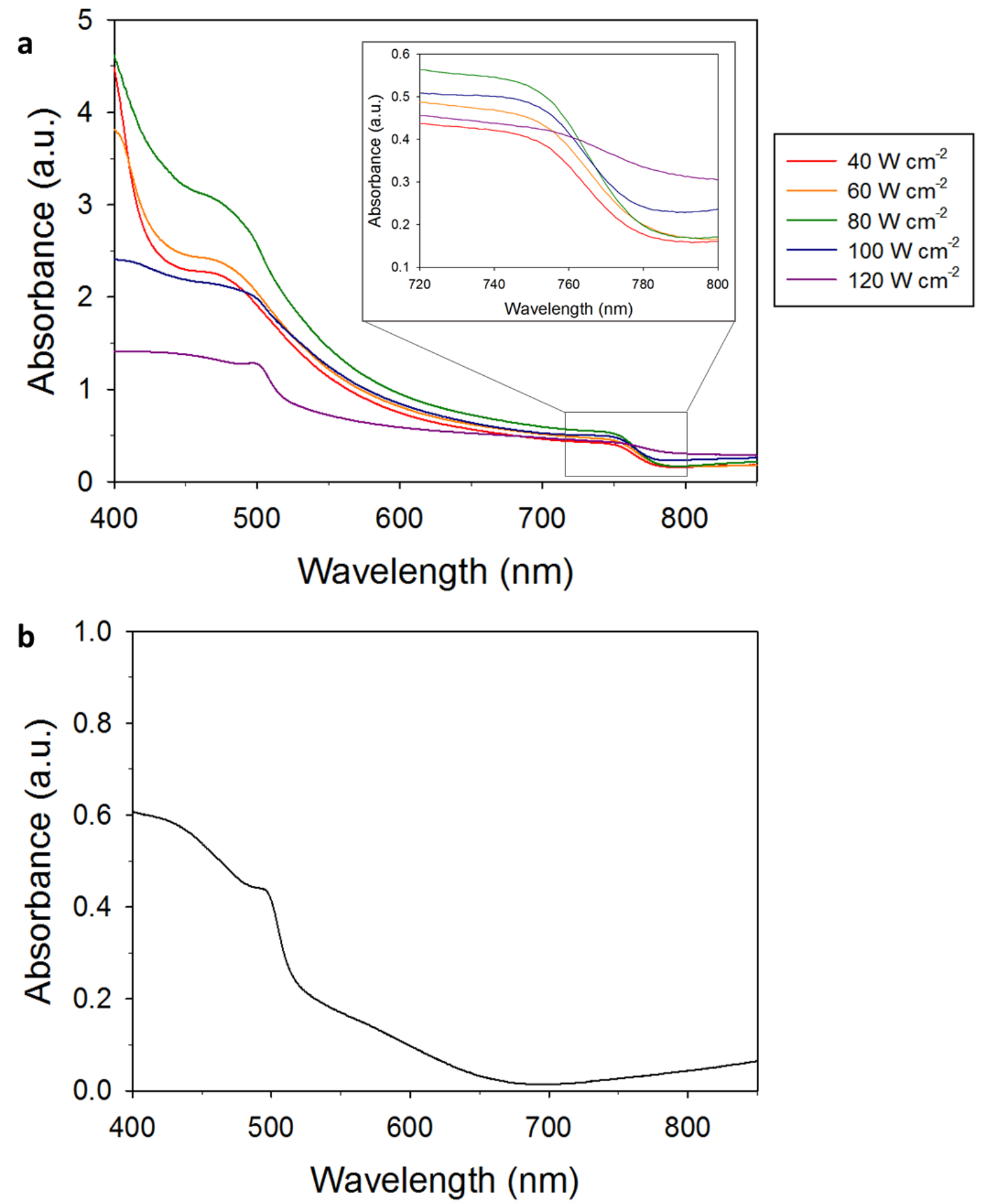

Figure S6. Absorbance spectra. a. $\mathrm{MAPbI}_{3}$, which are prepared by various laser irradiation power densities. Inset enlarges absorption edge of $\mathrm{MAPbI}_{3}$ perovskite around $780 \mathrm{~nm}$. The absorption edge tends to be shifted toward long wavelength region with increased power density. b. Absorbance of $\mathrm{PbI}_{2}$ film, showing strong increase in absorption near $500 \mathrm{~nm}$. This peak is also visible in absorbance of $\mathrm{MAPbI}_{3}$, which is laser-crystallized with power density over $100 \mathrm{~W} \mathrm{~cm}^{-2}$. 


\begin{tabular}{|c|c|c|}
\hline $\begin{array}{c}\text { Power } \\
\text { Density }\end{array}$ & Carrier lifetime, $\tau_{1}(n s)$ & Carrier lifetime, $\tau_{2}(n s)$ \\
\hline 40 & 0.90 & 6.3 \\
\hline 60 & 1.26 & 11.4 \\
\hline 80 & 1.60 & 13.4 \\
\hline 100 & 1.31 & 12.4 \\
\hline
\end{tabular}

Table S1. Summary of carrier lifetimes based on time-resolved photoluminescence (Figure 4b). Carrier lifetimes are extracted using bi-exponential functions with various laser power densities. Both $\tau_{1}$ and $\tau_{2}$ tend to increase with increased laser power density and show the longest lifetime at $80 \mathrm{~W} \mathrm{~cm}^{-2}$. 


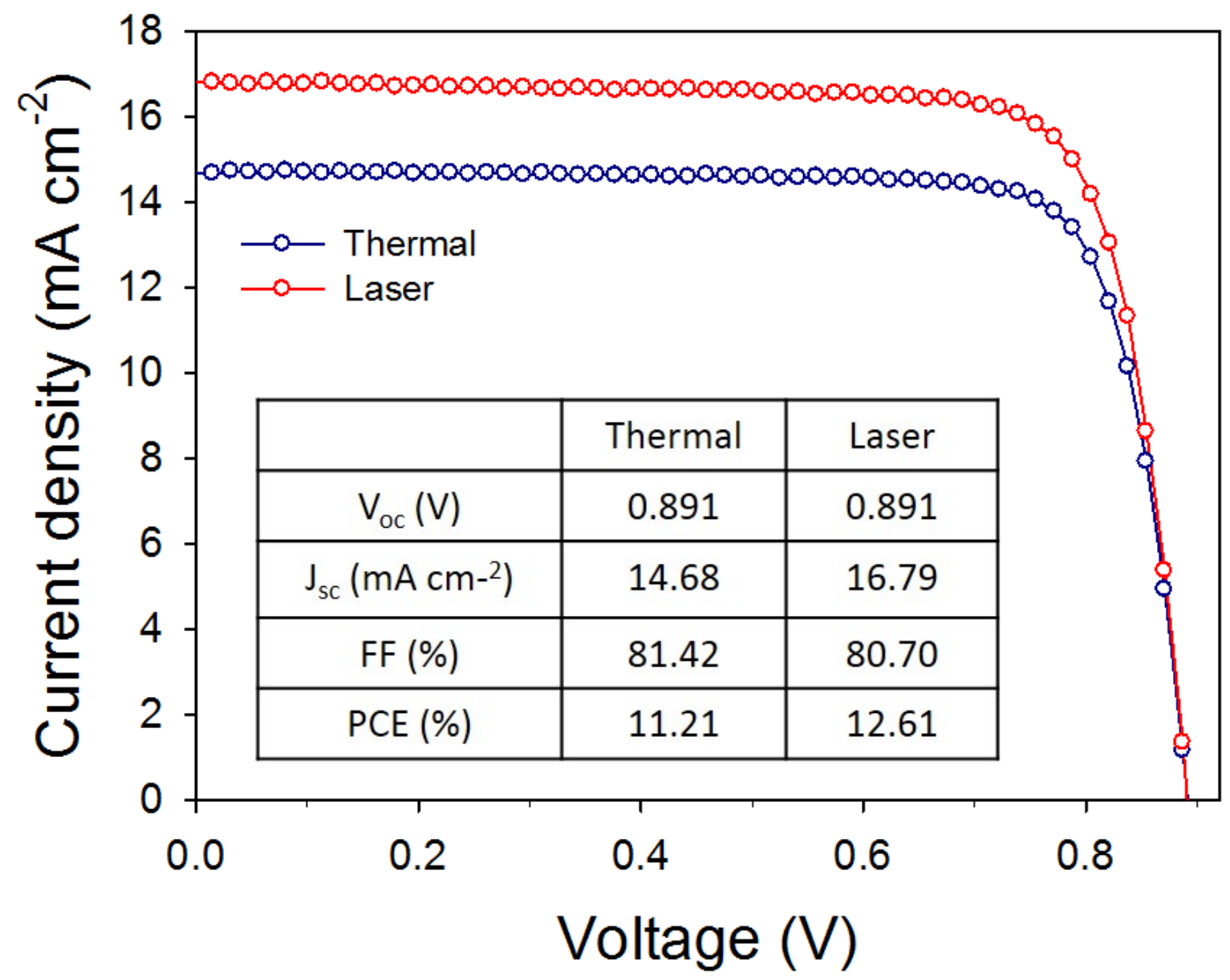

Figure S7. Solar cell performance comparison. The best $\mathrm{J}-\mathrm{V}$ characteristics of $\mathrm{MAPbI}_{3}$ perovskite solar cells which are prepared by controlled thermal annealing $\left(100{ }^{\circ} \mathrm{C}, 5 \mathrm{~min}\right)$ and laser crystallization ( $80 \mathrm{~W} \mathrm{~cm}^{-2}, 0.1 \mathrm{~mm} \mathrm{~s}^{-1}$ ), respectively. Laser crystallization of perovskite present comparable efficiency compared to conventional thermal treatment (Figure 4e). 


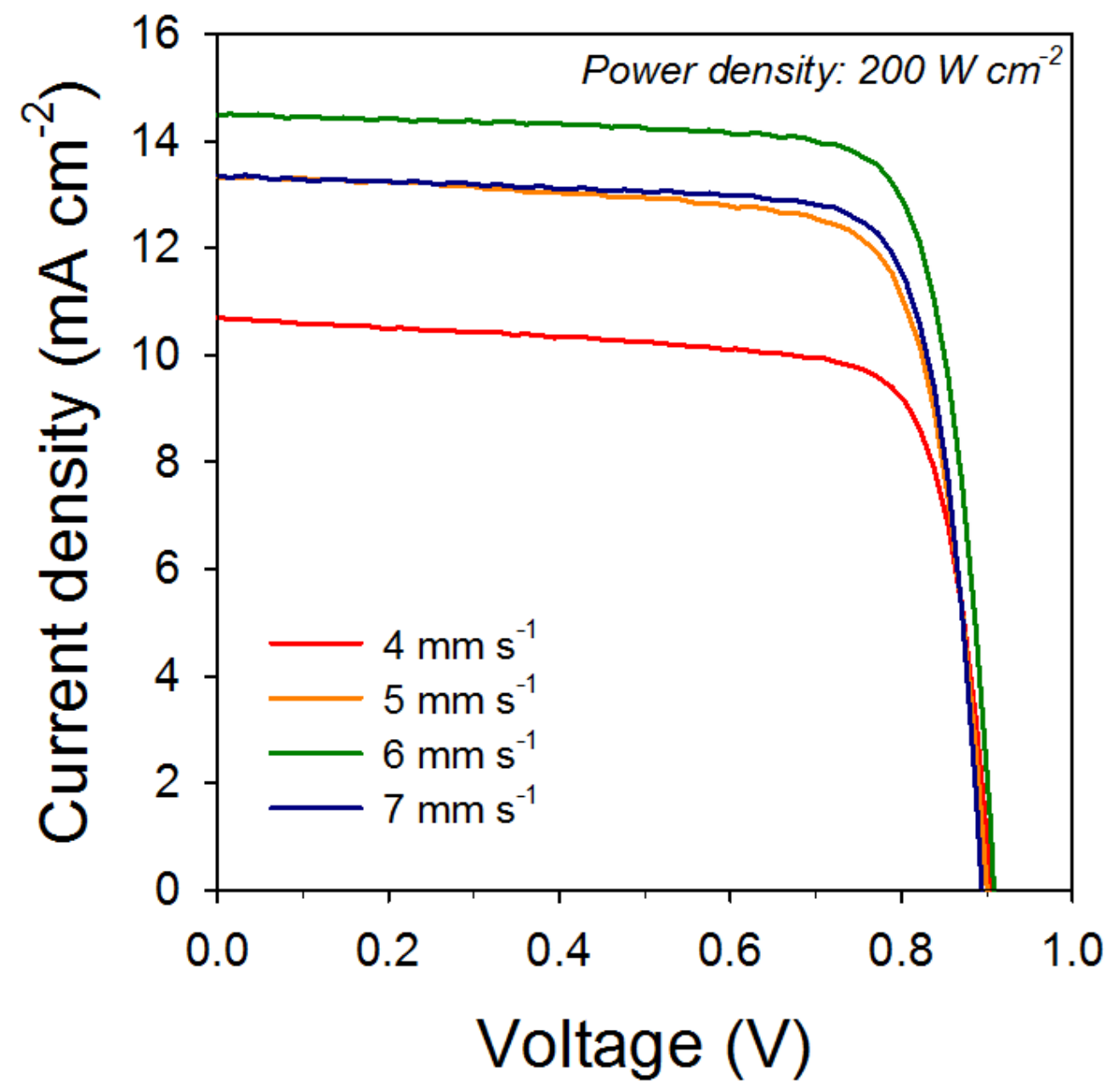

\begin{tabular}{ccccc}
\hline $\begin{array}{c}\text { Scan rate } \\
\left(\mathrm{mm} \mathrm{s}^{-1}\right)\end{array}$ & $\begin{array}{c}\mathrm{V}_{\mathrm{oc}} \\
(\mathrm{V})\end{array}$ & $\begin{array}{c}\mathrm{J}_{\mathrm{sc}} \\
\left(\mathrm{mA} \mathrm{cm}^{-2}\right)\end{array}$ & $\begin{array}{c}\mathrm{FF} \\
(\%)\end{array}$ & $\begin{array}{c}\text { PCE } \\
(\%)\end{array}$ \\
\hline 4 & 0.91 & 10.72 & 76.52 & 7.98 \\
5 & 0.90 & 13.37 & 76.43 & 9.89 \\
6 & 0.91 & 14.50 & 79.45 & 11.25 \\
7 & 0.89 & 13.36 & 79.26 & 10.18 \\
\hline
\end{tabular}

Figure S8. Solar cell performance of laser-crystallized $\mathrm{MAPbI}_{3}$ perovskite solar cells with fast laser scan rates. The devices were fabricated using rigid ITO/glass substrates with fast laser scanning with maximum allowed power density of $200 \mathrm{~W} \mathrm{~cm}^{-2}$ of our homemade laser system. Table summarizes solar cell parameters with scan rates. An efficient solar cells of PCE $11.25 \%$ without rigorous device optimization was attained with $6 \mathrm{~mm} \mathrm{~s}^{-1}\left(21.6 \mathrm{~m} \mathrm{hr}^{-}\right.$ $\left.{ }^{1}\right)$. 


\section{$808 \mathrm{~nm}$ diode laser}
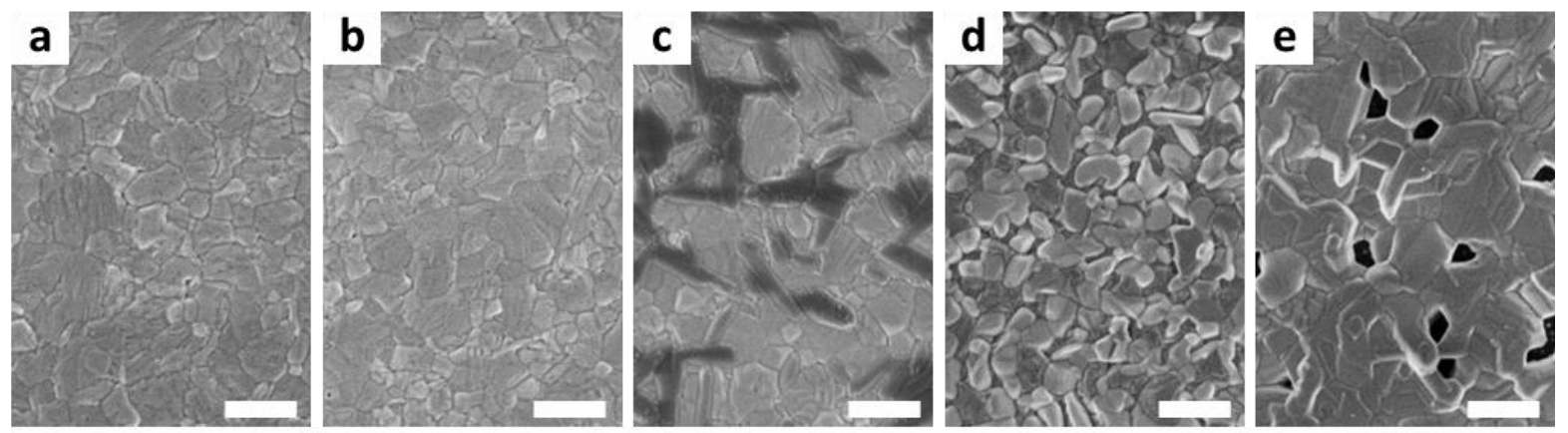

\section{$532 \mathrm{~nm}$ fiber laser}
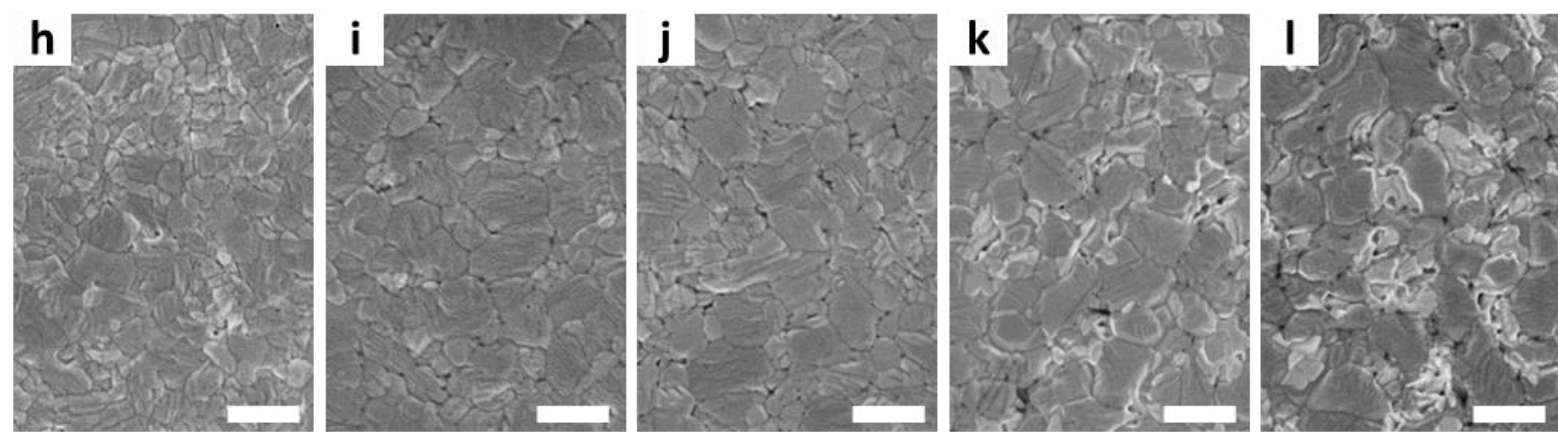

Figure S9. Feasibility of laser crystallization of $\mathrm{MAPbI}_{3}$ perovskite by $808 \mathrm{~nm}$ and 532 nm laser sources checked by SEM images (scale bar: $500 \mathbf{~ n m}$ ). $808 \mathrm{~nm}$ laser with power density of a) 271, b) 543 c) 814 d) 1086 and e) $1357 \mathrm{~W} \mathrm{~cm}^{-2} .532 \mathrm{~nm}$ laser with power density of h) 7.1 i) 7.8 j) $8.4 \mathrm{k}$ ) 9.2 and l) $10.2 \mathrm{~W} \mathrm{~cm}^{-2}$. Both lasers enables crystallization of perovskite precursor films and polycrystalline morphology is controllable with laser power densities. 